\title{
Reflexões e práticas identitárias de jovens da Cova da Moura (Amadora, Portugal)
}

Cláudia Vaz ${ }^{1}$ Instituto Superior de Ciências Sociais e Políticas, Universidade de Lisboa/CAPP, Portugal

Este texto foi adaptado da tese de doutoramento "Kova-M forever: Samplagens da Zona. Identidades de jovens da Cova da Moura". São dois os objetivos deste artigo: contribuir para a reflexão da noção de identidade e compreender as identidades de jovens da Cova da Moura, sobretudo no que respeita aos elementos nacionalidade e "raça". A recolha de dados assentou no método etnográfico, com recurso à observação participante, a entrevistas semi-estruturadas, conversas informais, recolba e análise de imagens (graffiti/tattoos) e letras de rap.

Palavras-chave: identidade, jovens, migrantes, bairro, Portugal

\section{O BaIrRo}

O bairro do Alto da Cova da Moura, localizado nas freguesias da Buraca e da Damaia, no concelho da Amadora, estende-se por uma área de cerca de 16,5 hectares.

As primeiras casas do bairro de génese clandestina, construídas em madeira, surgiram ainda na década de 1960 do século passado. Encontravam-se dispersas, embora centradas essencialmente em dois núcleos: um localizado junto à Quinta do Outeiro, onde funcionava uma vacaria, o outro junto à actual Avenida da República, próximo de uma pedreira desactivada, ocupado pela família Moura.

Embora o número de barracas, quer de habitação quer de apoio à agricultura, continuasse a aumentar, até 1974 a zona da Cova da Moura mantinha-se sobretudo como uma terra de cultivo de trigo e de criação de animais. Não acolhia, nesse ano, mais de 360 habitantes, de acordo com informação municipal.

1 Contato: cvaz@iscsp.ulisboa.pt 
A chegada dos chamados retornados ${ }^{2}$, sobretudo provenientes de Angola, vem alterar a distribuição e o tipo de construção das habitações neste espaço. Uma parte deles é instalada na Cova da Moura pelo então Instituto de Apoio aos Retornados Nacionais (IARN). As barracas de madeira começam progressivamente a ser substituídas por casas em alvenaria.

O surto de imigrantes africanos só ocorre mais tarde. Ao longo da década de 1980, é predominantemente constituído por cabo-verdianos. Na década seguinte, o bairro passa a acolher em maior número naturais de Angola, Guiné-Bissau e S. Tomé e Príncipe. A instalação de imigrantes do Leste Europeu e do Brasil é bem mais recente.

Aquelas duas populações, a de origem portuguesa e a de origem africana, estão na génese de uma das principais divisões do bairro, que ainda hoje persiste, estabelecendo um evidente contraste: o "quarteirão Europeu” e o "quarteirão Africano".

O "quarteirão Europeu” assenta na malha octogonal, onde prevalece o alinhamento das casas. A tipologia predominante é a moradia isolada ou em banda.

Já no "quarteirão Africano", as construções surgem livremente; à casa inicial vão-se juntando os anexos. Ainda hoje, os moradores continuam a adoptar este comportamento. A área das casas vai sendo aumentada, de acordo com as possibilidades económicas dos seus proprietários (muitas vezes com recurso ao djunta mô).

A divisão entre os quarteirões "Europeu" e "Africano" não deve ser entendida enquanto fronteira física com consequências na escolha dos itinerários e na ocupação do espaço. A origem da população não determina o tipo de relação que se estabelece entre os moradores do bairro.

Não se sabe ao certo quantos habitantes tem, ao certo, a Cova da Moura mas estimam-se em cerca de 6000 habitantes, apontando as estimativas conhecidas para uma percentagem de $60 \%$ de origem africana. Metade dos habitantes tem menos de 20 anos $^{3}$. Embora se verifique uma tendência para o crescimento do número de idosos na Cova da Moura (os maiores de 64 anos atingiam cerca de $7 \%$ dos residentes, em 2001), acompanhada de uma aparente redução das taxas de fecundidade, o Bairro mantém estruturas demográficas originais no contexto das freguesias que integra: cerca de $22 \%$ da população com menos de 14 anos (no concelho, não atingem 15\%) e quase $45 \%$ com menos de 24 anos.

Fenómenos como a gravidez precoce, a baixa taxa de escolaridade, a instabilidade familiar e o tráfico de armas e de droga, fazem com que este bairro seja muitas vezes mencionado pelos media de "bairro problemático".

2 Referência ao movimento de regresso de cidadãos portugueses residentes nas colónias africanas, após o 25 de Abril de 1974, em consequência da descolonização e a concessão de independência a Angola, Moçambique, Guiné-Bissau, S. Tomé e Príncipe e Cabo Verde. Estima-se que Portugal terá acolhido nesse período cerca de um milhão de pessoas.

3 Consultar site da associação Cultural do Moinho da Juventude http://redeciencia.educ.fc.ul.pt/moinho/requalif_bairro/caracteriza_se.htm 
Se o bairro, a “área natural”, não determina, não produz e reproduz, o ciclo de vida dos seus "filhos", certamente que o condiciona. Como veremos, crescer num bairro com as características do bairro da Cova da Moura não é o mesmo que crescer noutro qualquer espaço urbano, seja pela exiguidade das relações de proximidade social, seja pela ausência do estigma inerente ao próprio espaço.

\section{Noções e PRÁtiCAS DE IDENTIDADE}

\section{O CONCEITO}

Tratar as questões da identidade não é tarefa fácil. Tudo é, afinal, identidade. Trata-se de um conceito transversal a tantos outros conceitos e a tantas outras áreas do conhecimento. Como refere Moreira,

Qual grande maré, a noção de identidade submergiu no espaço de algumas décadas no conjunto das ciências sociais e humanas. Quer se trate de analisar realidades tão diversas como as transformações religiosas, as relações homem/mulher, as profissões, a vida familiar, a imigração ou os conflitos étnicos, a identidade impôs-se como uma palavra mágica. Como diz Lévi-Strauss não se situa numa só encruzilhada, mas em mais de uma. (Moreira 2006:15).

O conceito de identidade aqui apresentado, construído para explicar as identidades múltiplas de jovens da Cova da Moura, assenta em cinco pressupostos, são eles: a identidade é um processo de ser e tornar-se; a identidade de uma pessoa ou de um grupo pode ser analisada a partir de um recurso metafórico: o jogo de espelhos; as identidades são necessariamente constituídas de forma colectiva; o conceito de fronteira é indissociável do de identidade; neste trabalho, a categoria "raça" é entendida como categoria discursiva e não biológica.

Relativamente ao primeiro pressuposto, a identidade entendida enquanto um processo de ser e tornar-se, é reconhecer que este é um processo em constante construção e reconstrução. Aceitar que a identidade se reduz à dimensão do ser é aceitar que a identidade é exclusivamente essencialista. Assim, para se ser - ser cabo-verdiano, português, africano, negro, branco, etc. bastaria nascer. Hoje sabe-se que não é assim. A este propósito, Hall (2003:47) afirma que

No mundo moderno, as culturas nacionais com que nascemos constituem-se numa das principais fontes de identidade cultural. Ao nos definirmos, algumas vezes dizemos que somos ingleses ou galeses ou indianos ou jamaicanos. Obviamente, ao fazer isso estamos falando de forma metafórica. Essas identidades não estão literalmente impressas em nossos genes. Entretanto, nós efectivamente pensamos nelas como se fossem parte

4 Alusão à obra Os Filhos de Sanchez, de O. Lewis (1966), para quem a cultura da pobreza não só cria "um estilo de vida, altamente estável e persistente, herdado por cada nova geração dentro da mesma linha genealógica (...) convertendo-se ela própria numa subcultura" (op. cit.:24), como impossibilita qualquer agente social que a integre de romper com este "ciclo interminável". Esta abordagem "poverty as a way of life" (Lewis, 1966 ), influenciou uma série de investigadores sociais, entre os quais Liebow, autor de Tally's Corner. A study of Negro streetcorner men (1967), pode ler-se: "Negroes in poverty tend to be poorer than their white counterparts and tend more to remain in poverty over generations, so that poverty, like skin color, appears as a hereditary characteristic as well as a circumstance of social and economic life. The transmission of the life style of poverty from generation to generation has logically drawn attention to Negro family life as the context in which this transmission is assumed to occur" (Liebow, 1967:4-5). 
de nossa natureza essencial. ${ }^{5}$

O mundo dos "scapes appadurianos" (Appadurai 2000) é, assim, o mundo do "tornar-se"; é o mundo das pertenças desterritorializadas, deslocalizadas, transfronteiriças.

O segundo pressuposto, a identidade de uma pessoa ou de um grupo poder ser analisada a partir de um recurso metafórico: o jogo de espelhos, implica que a compreensão de que a perceção que temos do modo como somos olhados condiciona a imagem que construímos de nós enquanto indivíduos ou enquanto grupos. Novaes (1993:107) afirma que "é como se o olhar transformasse o outro em um espelho, a partir do qual aquele que olha pudesse enxergar a si próprio. Cada outro (...) é um espelho diferente, que reflete imagens diferentes de si”. Também para Soares et al. (2005:206) "a identidade só existe no espelho e esse espelho é o olhar dos outros". Podemos então afirmar que falar de identidade é falar de representação. Especificando o elemento identitário nacionalidade, Hall (2003:47) diz que

as identidades nacionais não são coisas com as quais nascemos, mas são formadas e transformadas no interior da representação. Nós só sabemos o que significa ser "inglês" devido ao modo como a "inglesidade" (Englishness) veio a ser representada - como um conjunto de significados - pela cultura nacional inglesa.

No que respeita ao terceiro pressuposto, ainda que as identidades sejam atributos individuais, elas são necessariamente constituídas de forma colectiva (não faz sentido pensar o indivíduo sem pensar o social). O individual e o colectivo estão enredados no quotidiano. Daí que a construção das identidades de jovens da Cova da Moura só faça sentido "situada" (no momento X, perante as circunstâncias Y e Z, o indivíduo A opta por ostentar o elemento identitário W). Os processos pelos quais as identidades individuais e colectivas se produzem e reproduzem são análogos. Não devem, por isso, ser analisados como se se tratassem de compartimentos estanques, de material arrumado em gavetas distintas. É neste sentido que a teorização da identidade deve contemplar o individual e o colectivo na mesma medida. Mais interessante do que proceder à distinção analítica entre identidade pessoal e identidade colectiva é olhar os vários elementos atendendo ao contexto no qual os discursos são produzidos.

O quarto pressuposto assenta na crença de que o conceito de fronteira é indissociável do de identidade. Basta pensar-se que a identidade se constrói na relação com o "outro", que pressupõe sempre a existência de um "outro" - individual/colectivo, real/imaginário. No fundo, o processo identitário constitui um processo de construção de fronteiras sociais, no sentido de esses "ajustamentos de fronteira" organizarem as relações que se estabelecem entre os indivíduos, em função das suas pertenças/não pertenças. A consciência de pertença a um grupo é indissociável da consciência de não pertença a outro grupo. No caso da Cova da Moura, é extremamente interessante estar atento a esta noção.

Finalmente, o quinto e último pressuposto é o de que, neste trabalho, consideramos a categoria "raça" enquanto categoria discursiva e não biológica. Como refere Hall (2003: 52), "nos últimos anos, as noções biológicas sobre raça [...] têm sido substituídas por definições culturais, as quais possibilitam que a raça desempenhe um papel importante nos discursos sobre nação e identidade nacional". Na Cova da Moura, o "ser português" está associado ao "ser branco", ainda que o ser da Cova da Moura, não esteja, necessariamente, associado ao "ser negro" (isto ao nível do discurso local).

5 Tradução do autor (todas as citações que se encontram traduzidas, ao longo do texto, da língua original para o português, são da autoria do autor). 
Ainda a propósito desta ideia de multiplicidade, subjacente ao "ser" e "tornar-se", é importante referir que está instaurada uma nova lógica. Em vez da lógica do "ou ... ou" - que pressupõe que os elementos são uma coisa ou outra - o processo identitário organiza-se sob a lógica do "e". Da mesma forma que não basta nascer português para sentir que se é português, também não basta sentir que se é português para se ser português. Assim, afirmar que a identidade é um processo de "ser" " "tornar-se", é afirmar que a identidade é sempre essencialista e circunstancialista. É uma "tomada de decisão" (Bourdieu) situada: no momento X, perante as circunstâncias Y e Z, o indivíduo A opta por ostentar o elemento identitário W.

As identidades de um indivíduo não têm lugar marcado, nem têm de se apressar a comprar bilhete, de forma a garantir o lugar. A "sala das identidades" é uma sala democrática: todos os elementos são livres de entrar, permanecer, sair e voltar a entrar, se for esse o seu desejo. A decisão de se colocarem ou não em pé, destacando-se assim dos restantes, depende do "filme" que esteja, naquele momento, a ser projectado. A invenção de um grupo de pertença não significa a extinção de outros.

A apresentação da identidade desta forma induz a suposição de que, por um lado, a identificação é sempre negociável e, por outro, depende de um desejo individual. No entanto, pensando em Kromo di Ghetto (caso-exemplar) ${ }^{6}$ ou em muitos outros jovens da Cova da Moura, faz sentido questionar: até que ponto é que ele escolhe responder "sou cabo-verdiano" - e não "sou português" - à questão "quem sou eu?".

Kromo di Ghetto nasceu e cresceu em Portugal, já lá vão 30 anos, mas o Estado português negou-lhe o reconhecimento da nacionalidade. É razão para perguntar, à semelhança de Hall (1998) em relação ao "Negro": "Que cabo-verdiano é este?" Ser "cabo-verdiano da Cova da Moura" é diferente de ser "cabo-verdiano de Cabo Verde". Os "cabo-verdianos da Cova da Moura" não são todos iguais, assim como também não o são os “cabo-verdianos de Cabo Verde”.

A este respeito, é interessante a distinção feita por Jenkins (2006) entre "identificação nominal" e "virtual", entre o "nome" e a "experiência" inerentes a uma identidade. Indivíduos que partilham a mesma identidade nominal podem não partilhar a mesma identidade virtual, na medida em que a vivência desse elemento, assim como o efeito que causa nas suas vidas, podem ser distintos.

De facto, a atribuição da mesma designação a diferentes indivíduos não implica que sejam afectados por ela de forma semelhante. "Ser rotulado não é nem unidireccional nem determinante" (Jenkins 2006:77).

Também Woodward (2004) chama a atenção para esta circunstância (aliás, à semelhança de Maalouf, 1991, o qual utilizou a imagem do bilhete de identidade).

Os nossos passaportes dão-nos um nome, descrevem-nos e localizam-nos. Um passaporte descreve um indivíduo; atribui um nome a uma pessoa. Determina igualmente a que grupo, em particular a que nação, essa pessoa pertence. Um passaporte selecciona outros elementos-chave da identidade, que incluem naturalidade, estado civil, idade, residência e número de bilhete de identidade. Todos juntos, posicionam-nos e dão-nos um lugar na sociedade em que vivemos. No entanto, não nos dizem nada sobre a forma como nós ocupamos essas posições ou sobre o que significam para nós. Os pormenores de um passaporte não revelam os sentimentos

6 Kromo di Ghetto e outros sujeitos de investigação são referidos como "casos exemplares" no sentido de "casos tipo", de sujeitos que ilustram determinadas categorias analíticas. 
de uma pessoa. ${ }^{7}$ (Woodward 2004:7).

Esta questão de um mesmo nome, uma mesma designação, poder ser sentida de forma distinta por diferentes pessoas - ou mesmo poder ser sentida de forma distinta pela mesma pessoa, em momentos diferentes - remete-nos para uma particularidade da identidade, que é ser um "casaco de Arlequim" ou uma "matrioska": os elementos identitários que caracterizam um indivíduo são múltiplos, como múltipla e variável é a forma como são vividos.

Ainda em relação à distinção entre identificação nominal e virtual, deve sublinhar-se o facto de ser meramente analítica. No dia-a-dia dos indivíduos, ambas as identificações surgem como "reais" e indissociáveis.

O nominal e o virtual são aspectos do mesmo processo. (...) De um lado, existe a atribuição de nomes a indivíduos, por eles ou por outros. Do outro, as acções dos indivíduos e as respostas de outros, que são experiências inter-relacionadas. Toda a identificação combina o virtual e o nominal. ${ }^{8}$ (Jenkins 2006:78).

\section{No terReno: "SEM ChÃo PARA PISAR"}

Vêm os cabo-verdianos de Cabo Verde e dizem-nos que não somos iguais a eles, que não somos cabo-verdianos. Eu costumo dizer-lhes que também era melhor que assim fosse, que passados 20 anos continuássemos iguais. Depois vêm os portugueses e dizem-nos que não somos portugueses. Isso fica a bater na nossa cabeça.

Issoé confuso?

Mais do que isso, ficamos sem chão para pisar, ficamos sem ter onde nos agarrar.

[Excerto de entrevista a Chullage]

É este o drama dos filhos da diáspora. Referindo-se aos crioulos "mexicanos" e "chilenos", Anderson (1991:88-89) observa que "nascidos nas Américas, não poderiam ser verdadeiros espanhóis; logo, nascidos em Espanha, os peninsulares não poderiam ser verdadeiros americanos”.

Uma questão pode, desde já, colocar-se: afinal, o que é ser um verdadeiro espanhol, americano, português, cabo-verdiano, galego, "cova-mourense"? A adjectivação das nacionalidades como verdadeiras/falsas assenta na essencialização das mesmas. Fará sentido manter a lógica da adjectivação neste "mundo appaduraiano"?

Os testemunhos que se seguem permitem compreender a pertinência das questões colocadas. Por mais numerosas que fossem as categorias-tipo entretanto criadas, haveria sempre a possibilidade de continuarem a surgir respostas diferentes à pergunta clássica dos estudos sobre a identidade - "quem sou eu"?

A questão avançada por Jenkins do "ser" e do "sentir", ou do "ser" e do "tornar-se", enquanto elementos importantes no estudo das identidades, é, pois, central para a compreensão desta matéria. Não basta "ser" cabo-verdiano(a)/português(a) para que os casos-exemplares se identifiquem como tal. Se nuns casos "são" portugueses mas não se "sentem”, noutros "não o são", mas acreditam que se o fossem "se sentiriam". Outros não o "são", nem poderiam vir a "sê-lo", por acreditarem que os "outros" nunca os veriam enquanto tal. Outros reclamam por um "retorno à etnia" (Agier 2001). Outros ainda são autores de novas categorias para a sua situação.

7 Tradução do autor.

8 Tradução do autor. 
As situações são, portanto, múltiplas.

Outro aspecto a ter em atenção é o da não-exclusividade dos elementos identitários ostentados nos momentos etnográficos apresentados. $\mathrm{O}$ facto de um jovem, num momento $\mathrm{A}$, responder que é cabo-verdiano, não significa que noutros momentos não possa afirmar-se como português, como africano, ou assumir qualquer outra condição. Se é verdade que num momento somos uma coisa, não é menos verdade que em vários momentos somos, ou temos a possibilidade de ser, muitas outras coisas. As identidades múltiplas não são sinónimo de identidades "mentirosas", mas sim de identidades "desterritorializadas", "translocais", "transfronteiriças". São uma consequência da construção de "mundos imaginados" (Appadurai 2000).

Também Hall chama a atenção para a subjectividade inerente a este processo, assim como para a importância de atender ao contexto no qual os elementos surgem.

Estamos constantemente em negociação, não com um único conjunto de oposições que nos situe sempre na mesma relação com os outros, mas com uma série de posições diferentes. Cada uma delas tem para nós o seu ponto de profunda identificação subjectiva. Essa é a questão mais difícil da proliferação no campo das identidades e antagonismos: elas frequentemente se deslocam entre si. (Hall 1998:346)

Quando perguntei a Ticha (caso-exemplar) quem é ela, como é que se vê, respondeu, sem hesitar: "sou cabo-verdiana”. Razão: apesar de ter nascido em Portugal, foi essa a nacionalidade que lhe foi atribuída à nascença - filho de cabo-verdiano era, de acordo com a lei que estava em vigor, cabo-verdiano.

\section{Quem és tu?}

Sou cabo-verdiana.

Nasceste em Cabo Verde?

Não, nasci em Almada.

E mesmo assim consideras-te cabo-verdiana?

Claro ... não é assim que me consideram? Eu não tenho Bilhete de Identidade português.

Ese tivesses?

Ah, aí já era diferente... assim já era portuguesa.

[Excerto de entrevista a Ticha]

Os dois testemunhos que se seguem revestem-se de um duplo interesse: a situação em si e o facto de Tugs e Carla (casos-exemplares) serem irmãos - serem filhos dos mesmos pais e terem nascido no mesmo hospital não foi suficiente para que lhes fosse atribuída a mesma nacionalidade. Um é português, o outro cabo-verdiano. A fronteira que os separa é de natureza política, é a da Lei da Nacionalidade: de um lado da fronteira estão os que nasceram antes de 1981, do outro os que nasceram em data posterior.

Quem és tu?

Sei lá...

Tens nacionalidade portuguesa?

Tenho. Mas não me considero português.

Mas tens B.I. português?!

Sim, mas não sou português.

Então és o quê?

Sou cabo-verdiano.

Alguma vez foste a Cabo Verde?

Não.

Então por que é que te sentes cabo-verdiano? 
Por causa dos meus pais. [Excerto de entrevista a Tugs]

Sou cabo-verdiana... nem que seja por uma questão de orgulho.

Porquê "nem que seja por uma questão de orgulho?"

Então, quando vou a qualquer lado e me perguntam o que é que eu sou, é claro que, olhando para mim

[referindo-se ao facto de ser negra], não estão à espera que diga que sou portuguesa. E mesmo quando o

faço, há sempre quem diga: "Não, os teus pais". Portanto, o que é que me resta se não ser cabo-verdiana?

Gostavas de ir morar para lá?

O que é que eu ia para lá fazer?

[Excerto de entrevista a Carla]

Independentemente de o serem ou não, sentem-se cabo-verdianos "por causa dos pais" e dos "outros", que não os deixam esquecer a sua condição de filhos de imigrantes.

No entanto, sentirem-se cabo-verdianos não significa que conheçam Cabo Verde e/ou que gostassem de ir viver para o país. "O que é que eu ia para lá fazer?" é uma pergunta que ilustra, em parte, a afirmação de Hall a propósito dos filhos da diáspora: "Se eles retornassem a suas cidadezinhas de origem, o mais tradicional deles seria considerado 'ocidentalizado' - senão irremediavelmente diasporizado" (2000:76). É que, no caso de Carla, não estaria "a retornar à sua cidadezinha de origem", estaria a ir para a "cidadezinha de origem" dos seus pais. É esta a situação em que se encontram muitos dos jovens da Cova da Moura.

Uma outra categoria de identificação bastante vulgar neste espaço é a de “Africano". Kromo di Ghetto (caso-exemplar) ilustra esta ideia.

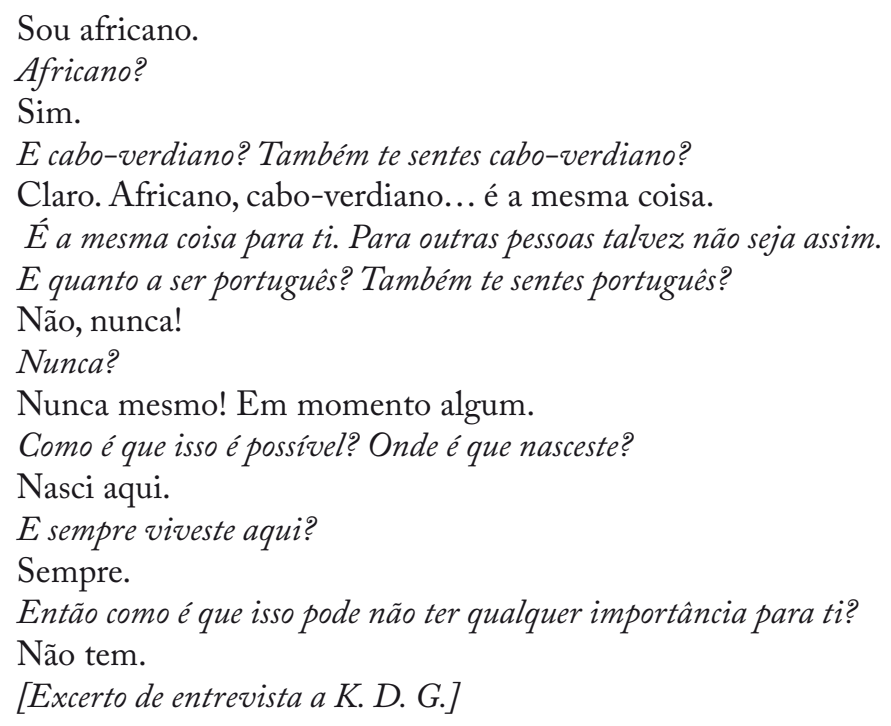

Quando Kromo di Ghetto diz: "Africano, cabo-verdiano... é a mesma coisa", deve acrescentar-se que é a mesma coisa para ele e para muitos da sua geração, mas não o será para os seus pais e os seus avós. Quando se pede a um cabo-verdiano - de Cabo Verde - que responda à questão "quem sou eu?", o mais provável é que responda, simplesmente, "cabo-verdiano".

\section{QUE PORTUGUÊS É ESSE?}

O cuidado que procuro ter em diferenciar os cabo-verdianos de Cabo Verde dos cabo-verdianos da Cova da Moura, sobretudo os que já nasceram e/ou cresceram em Portugal, tem implícita uma questão colocada por Hall, a propósito dos negros da diáspora: "que 'negro' é esse 
na cultura negra?" (1998:335). Ou seja, que cabo-verdiano é esse? De que "cabo-verdiano" se está a falar? Da mesma forma, quando Kromo di Ghetto se diz "africano" - que "africano" é esse na - e da - Cova da Moura?

Subjacente a estas “declarações identitárias” (Agier 2001) está, precisamente, a desterritorialização de África e de Cabo Verde (neste caso específico), a sua transformação num "universal particularizável": um conceito-África-Cabo Verde que pertence a todos aqueles que dele queiram apropriar-se, com o qual queiram identificar-se (Amselle 2001).

A inclusão no grupo dos "africanos" e a exclusão do que reúne os "portugueses" é intencional: se, por um lado, oferece um "chão" - ainda que virtual - que pode ser "pisado" e "agarrado" por todos os $\mathrm{Negros}^{9}$, fomentando a solidariedade intragrupo, por outro, marca a sua posição de revolta, de inconformismo, com a situação em que se encontram.

A identidade africana, esta identidade africana, é o produto de um contexto específico - o contexto urbano, no qual, constantemente, se chama a atenção para as diferenças, contrastes e comparações (Appadurai 2000). Constitui, afinal, uma estratégia de adaptação a um ambiente concreto: "A africanidade e a condição negra parecem ter se transformado em função do contexto em que vivem. Dizer da 'africanidade' não é afirmar necessariamente a África; trata-se de uma afirmação de origem, mas não da mesma forma que seus pais o fazem” (Gusmão 2004:153).

É ainda interessante referir que, no terreno etnográfico, esta categoria-África foi apropriada apenas pelos jovens do sexo masculino. Isto não significa que as raparigas não se identificam com África, significa sim, que nenhuma me disse que é africana, que se sente africana. A identificação mais comum foi com Cabo Verde, a "terra de seus pais".

Até que ponto esta apropriação de "África" não será uma consequência da desterritorialização da "vida de gueto"? Até que ponto não corresponde à noção de que o habitus de rua é transfronteiriço, de que existem muitos outros jovens, em muitos outros espaços, a viver e a sentir experiências similares? Até que ponto não se está em presença de uma estratégia "translocal" de conquista de respeito e de visibilidade do "nós"? Esta forma de expressão, que atinge o seu apogeu com a cultura Hip Hop, é sobretudo masculina.

A letra do tema musical "É mas um hiztória tristy", da autoria de S. D. D. e Kromo di Ghetto, é ilustrativa desta instrumentalização da "raça", da ideia de "nação africana" e da "vida de gueto" (muitas outras letras poderiam ser apresentadas; as suas histórias, as histórias que contam, estão pejadas destas noções).

É mais uma história triste

Mas nigga não desistas

Africanos na terra dos brancos têm que fazer mais do que resistir

Buraka Kova M mafia click mas continua sempre, sempre a persistir

Enquanto existires,

Vão vendo a nossa realidade como o meu Nigga Kromo diz, é mais uma história triste mas continuem a insistir e sempre a persistir enquanto existirem, contra quem nunca nos ajudou mas sempre nos maltratou

Por isso abre os olhos povo africano, pronto para a Revolução e a Coligação

Para todos os pretos dos guetos tomem atenção

9 Esta questão da "Nação Negra", da instrumentalização da "raça", será tratada mais à frente (em "Uma identidade nacional inventada?"). Trata-se da ideia de África = Etnia + "Raça". 
Alterem a mentalidade

Fortaleçam a irmandade para podermos combater $[\ldots]^{10}$

Em "É mais uma história triste", é muito clara a associação da categoria raça e da categoria nação: ser africano é ser negro, ser português é ser branco. Categorias como "africano", "nigga" e "negro", proporcionam a estes jovens o desenvolvimento de uma consciência colectiva "além-terra”, de um "nós deslocalizado", um "nós” que, não estando ancorado a um tchan real, está "situacionalmente" ligado a várias "ideias-de": ideia de "África”, ideia de "Negro", ideia de "Cabo Verde".

O que está aqui subjacente é a racialização das categorias português e "outros". Esta é uma das justificações para o facto de muitos destes jovens não se reconhecerem como portugueses, mesmo que oficialmente o sejam. "Infindável jogo de espelhos", como refere Silva (2003:31): eu sou aquilo que penso e sinto que sou, mas também sou aquilo que penso que os outros pensam que eu sou.

Os "filhos da diáspora" têm despertado a atenção dos insiders dos países de acolhimento para o surgimento de um novo tipo de insider, neste caso, um novo tipo de português, um "português negro". A contradição reside naqueles que não reconhecem a existência deste "ser português" (Les Back 1996:149).

O seguinte episódio ilustra esta questão. São episódios vulgares como estes que alimentam e perpetuam estigmas, estereótipos e preconceitos.

Uma vez fui ao SEF [Serviço de Estrangeiros e Fronteiras] tratar de um assunto. Assim que lá entrei, tirei logo o BI da mala, porque sabia que ia ser necessário. Quando chegou a minha vez, sentei-me e pus os documentos à vista. A senhora que lá estava pediu-me a autorização de residência. Disse-lhe que não tinha. "Não vê que tenho BI [cartão de identificação]? Então, não preciso dessa autorização". A funcionária continuou a insistir comigo. Disse-me que sem esse documento não daria seguimento ao pedido. Ela não foi capaz de entender que, apesar de ser preta eu sou portuguesa.

A hesitação da funcionária do SEF é sintoma de que, para algumas pessoas, não é possível ser-se negro e simultaneamente really Scottish, really British ou "verdadeiro português".

Identificada, homogeneizada e categorizada, numa palavra, diferenciada enquanto minoria étnica ou racial, com base num mesmo atributo físico, a tendência é a generalização da tradicional condição de "imigrante" a todos os que partilham desse mesmo atributo, com os respectivos efeitos sociais decorrentes do imaginário estereotípico associado a essa mesma condição. Nesta medida, o preconceito precede a discriminação e, mesmo sendo português, o "negro" continua a ser visto como "estrangeiro", mesmo sendo legalizado a sua condição acaba por revestir-se de alguma natureza intrusiva (...). (Ferreira 2003:28)

É por isso que, quando alguns indivíduos fogem ao que é suposto, quando não encaixam nos rótulos criados para o seu grupo, rapidamente são inventadas outras categorias que perpetuam e simplificam as diferenças percepcionadas. Daí o aparecimento de designações como

10 Texto original (em crioulo): "É mas um Hiztória tristy / Mas nigga ka bu disisti / Afrikanus na terra Brankus tem ki ta fazi mas ki resisty / Buraka Kova M mafia click ta kontinua sempri ta presisty / Inquantu nu existy / É si ba ta cheka nus realidadi e sima nha Nigga Kromo as ta flau é mas um Hiztória tristy ma nu ta kontinua ta insisty e sempri ta presisty inquantu nu existy kontra kenha ki nunca atchudanu ma ki sempri maltrata nu / Pur issu nhós abri otcho puvu Afrikanu / Pronto pa Revoluçon e pa Koligaçon / pa tudu pretu di guetto nhós pa ta tuma atençon / Altera mentalidadi / Fortaleci Irmandadi pa nu podi infrenta [...]" 
bounty $^{11}$ - "preto por fora, mas branco por dentro" - ou bolicao ${ }^{12}$ - branco por fora, mas negro por dentro (Lewis et al.1997:127). Ou seja, rótulos criados para lembrar ao indivíduo que o seu "ser" não chegou a "tornar-se" naquilo que o colectivo "imaginou" para ele.

Como se pode constatar, a "negritude" é um elemento importante da sua identidade ao nível do discurso supra-local, mas não ao nível do discurso local. Ou seja, é importante na diferenciação do "outro" mas não do "nós" (Les Back 1996). O que acaba, aliás, por funcionar como um elemento de diferenciação positiva face ao "outro", aquele que, contrariamente a si, discrimina em função da "raça".

Les Back (1996) identifica dois elementos discursivos em torno da questão da "nossa área", da "nossa zona": o discurso da harmonia e o discurso da comunidade negra. Também os ouvi no terreno.

No discurso da harmonia, a afirmação mais comum é a de que a comunidade local está livre de tensão racial e imperam as boas relações entre os seus elementos (sejam eles brancos ou negros). A afirmação de Kromo di Ghetto - "levo a life de um africano descendente de cabo-verdianos na tuga" - personifica, assim, a Cova da Moura, espaço onde os vários elementos coexistem sem entrarem em oposição.

Em outros contextos, e muitas vezes a par com este discurso, uma fórmula adicional é utilizada para marcar a área como sendo "negra", um espaço onde negros lutaram para terem algo seu. Eles aparentam ser "donos do território" - é o nível do "discurso da comunidade negra". Este discurso não é utilizado como alternativa ao "discurso da harmonia", mas como forma de particularizar experiências. A raça surge agora enquanto elemento identitário legítimo.

De acordo com este sistema, a identidade negra é definida em termos de reacção ao racismo e à discriminação, mas também como um processo criativo de reconstrução identitária, sendo este último elemento expresso em termos de "raízes" (Les Back 1996:146). No fundo, esta tensão entre a relevância de ser da Cova da Moura, enquanto nosso chão, e ser um outsider negro espelha as "novas etnicidades" deste mundo desterritorializado: "Novas etnicidades são produzidas em parte através de uma tensão entre influências globais e locais. Novas etnicidades não só desafiam o significado de ser negro, mas também colocam em questão o significado de ser Britânico" (Les Back 1996:4), ser português, ser da Cova da Moura, ser um português da Cova da Moura, ser um "cova mourense" português, etc.

\section{UMA IDENTIDADE "NACIONAL" INVENTADA?}

Portugal não lhes deu um "chão", em nome do jus sanguinis; Cabo Verde não o perpetuou, em nome do jus soli ${ }^{13}$. Os jovens da Cova da Moura inventaram um, o qual designam como seu. A criação desse "lugar" conferiu-lhes um sentido de "nação", uma "nação imaginada", no sentido de um "lugar" de pertença, um "lugar" que tem a particularidade de poder ser "pisado", de não estar reduzido a uma "ideia-de", um "lugar seu".

11 Bounty - Nome de um chocolate de côco.

12 Bolicao - Espécie de pão doce com recheio de chocolate.

13 Por jus sanguinis entende-se a atribuição de nacionalidade em função dos laços de sangue; por jus soli, com base no local de nascimento. Diferentes tradições culturais e políticas justificam a opção, em cada país, por uma ou outra das vias. 
A este propósito, Seton-Watson diz que "tudo o que pode dizer é que uma nação existe quando pessoas em número significativo numa comunidade consideram elas mesmas que formam uma nação, ou se comportam como se assim fossem ${ }^{14 "}$ (citado por Anderson 1991: 25). De facto, os jovens que conheci no decurso da investigação não têm com a Cova da Moura apenas uma ligação assente no facto de residirem no bairro. As afirmações de Santinho - "ela é tudo para mim" - e de Outlaw - "K-M forever" - são reveladoras de uma relação de amor. Mas, sobretudo, da natureza da relação do homem com o seu "chão".

A expressão "Cova da Moura para sempre", comummente utilizada pelos jovens do bairro, quando questionados sobre a importância que esse lugar tem para si, traduz a forte ligação que estabeleceram com o "lugar".

O caso dos jovens da Cova da Moura é particularmente interessante. Não se limitaram à partilha de um sentimento comum desterritorializado, ao reconhecimento de "trans-similaridades" (por oposição aos "trans-outros"). Criaram um "lugar”, criaram um "chão", uma "terra”. Criaram uma nova tradição. Não se trata de mixing heritages, do tipo 30\% cabo-verdiano + 30\% português $+20 \%$ africano $+20 \%$ nigga, mas de criar uma nova herança (Les Back 1996). Agora, aos "lugares virtuais" presentes na sua identidade (independentemente de serem ou não ostentados num momento $X$, eles estão lá), juntou-se um "lugar real”, um espaço que conquistaram - o bairro do Alto da Cova da Moura.

“Todos nós nos originamos e falamos a partir de algum lugar: somos localizados - e neste sentido até os mais modernos carregam traços de uma etnia. Como Laclau argumenta, parafraseando Derrida, nós só podemos pensar 'dentro de uma tradição”, como refere Hall (2000:83). Até as tradições são objecto de construções e reconstruções.

Jovens de todas as comunidades expressam certa fidelidade às "tradições" de origem, ao mesmo tempo em que demonstram um declínio visível em sua prática concreta. Declaram não uma identidade primordial, mas uma escolha de posição do grupo ao qual desejam ser associados. Portanto, as generalizações se tornam extremamente difíceis diante dessa complexidade cultural. (Hall 2000:66-67)

Estes jovens não deixaram de se identificar com a cultura dos seus pais, com a cultura de origem. É com orgulho que se afirmam cabo-verdianos, que ostentam as pulseiras e os colares de contas de Cabo Verde, que falam crioulo, que utilizam a rua como extensão da casa, que participam nas festas tradicionais (por exemplo, Kolá San Jon) ${ }^{15}$, que assistem às actuações do grupo de batuque, que consomem comida típica da terra, etc. No entanto, se não há duas pessoas iguais, também não há "gerações-cópia": os "filhos da Cova da Moura" não são só "filhos de Cabo Verde". São "filhos” de muitas outras coisas, mas são também, eles próprios, "pais": criaram a "sua" Cova da Moura, atribuindo-lhe o significado de "nosso chão".

Estando dependente de um determinado sentimento de pertença - um "ser" que depende de um "sentir" - a "nação afirma-se assim como opção" (Moreira 2007:36).

"É útil lembramo-nos de que as nações inspiram amor, e muitas vezes um amor profundamente abenegado. Os produtos culturais do nacionalismo - a poesia, a ficção em prosa, a música, as artes plásticas - demonstram esse amor muito claramente, em milhares de estilos e formas

14 Anderson (1991:25) refere que é possível traduzir "consideram elas mesmas" por "imaginam elas mesmas" - no sentido de "comunidades imaginadas".

15 Iniciativa organizada pela Associação Cultural Moinho da Juventude. 
diferentes"(Anderson 1991:193).

Muitos jovens do bairro mostram-no no seu discurso, nas suas acções quotidianas. Criaram símbolos que, por favorecerem o sentimento de união, reforçam a sua auto-estima, designadamente: a evocação do nome do bairro nas letras de rap e nos "riscos" nas paredes (nem que seja nos $\left.\operatorname{props}^{16}\right)$; a criação de roupa de marca $K-M^{17}$; alusões ao bairro nas tatuagens que ostentam (caso do Santinho) e nos sites e blogs da internet. Já muitos dos rapazes - quais "Arlequins pós-modernos" - fazem questão em exibir uma "pele K-M" (são muitos aqueles que ostentam tatuagens onde pode ler-se "Cova da Moura" ou "Kova-M") por baixo de uma camisola também $K-M$.

Foi a invenção desta "ideia de" nação - assente na etnicização da diferença - que permitiu aos jovens a conversão de um estigma numa bandeira. "São niggas e são do ghetto, são da Cova da Moura. (...) querem demonstrar que a sua cultura tem valor (...)" (Juan 2007:18). A identificação com o bairro deixou de ser, para a maioria, um motivo de embaraço, de vergonha. Ser da Cova da Moura passou a ser sentido e vivido com orgulho, esteja-se onde se estiver.

\section{ConcLusão}

Pode afirmar-se que, mais do que uma forma de "quebrar o gelo" (Goffman [1963] 1980:128), de mostrar ao grupo dos "normais" que não têm razão nos seus juízos de valor, os jovens da Cova da Moura aqui retratados, inventaram uma forma de transformar uma identidade negativa, que lhes foi imposta, numa identidade positiva - os jovens do bairro estão "estrategicamente" (Anderson 1991:177) a mostrar que diferença não é sinónimo de defeito.

Agier fala em "criatividade cultural" (2001:9). Lewis et al. (2000:119) falam em "criatividade social". No caso destes jovens, penso que a expressão "criatividade pela sobrevivência" exprime a realidade de forma mais adequada. Será por acaso que a Cova da Moura só agora adquiriu esta dimensão de "nação étnica"? Não pode este fenómeno ser enquadrado num esforço levado a cabo pelos jovens, assim como pelas instituições do bairro - destacando-se a acção desenvolvida pela Associação Cultural Moinho da Juventude - no sentido de mostrar o "outro lado" da Cova da Moura? Mostrar que a vida no bairro é kutziana ${ }^{18}$ - "é normal" - e que não existem só "pessoas más"?

A percepção do seu não reconhecimento como portugueses e a sua condenação a eternos “desviantes" (Goffman [1963] 1980), podem ter acabado por empurrá-los para a criação de um "espaço" onde a sua humanidade lhes fosse reconhecida (o que é expresso das mais diversas formas).

16 Palavra que na gíria do Hip Hop significa dedicatória.

17 É interessante fazer referência, à origem deste produto, que remonta às primeiras t-shirts confeccionadas para homenagear os jovens que faleceram desde 2001. O seu dinamizador é um jovem que trabalha numa empresa gráfica, onde também se fazem estampagens de t-shirts. O sucesso inicial foi tanto que começou a encarar a actividade como uma oportunidade de negócio. O produto já foi mesmo exibido num programa de televisão.

18 Alusão a Kutz, um dos casos-exemplares, para quem tudo "é normal". 
Uma das principais mudanças que estes jovens introduzem em relação aos seus pais reside na invenção de um tchan, que podem pisar e chamar seu. Nascidos e criados num "lugar" onde são reconhecidos como pertencendo a outro "lugar", que também não os reconhece como seus, estes jovens acabaram por criar o seu próprio "lugar", o qual é cantado, riscado, vestido, tatuado e levado para onde quer que vão.

\section{REFERÊNCIAS}

Agar, Michael.1996. The professional stranger: an informal introduction to ethnography, San Diego: Academic Press.

Agier, Michel. 2001. "Distúrbios identitários em tempos de globalização.” MANA 7 (2): 7-33. Allport, Gordon. 1979 [1954]. The Nature of Prejudice. Cambridge: Perseus Books.

Amselle, Jean-Loup. 2001. Branchements. Anthropologie de IÚniversité des Cultures. Paris : Flammarion.

Anderson, Benedict. 1991. Comunidades Imaginadas. Reflexões Sobre a Origem e a Expansão do Nacionalismo. Edições 70. Lisboa: Perspectivas do Homem.

Appadurai, Arjun. 2000. Dimensões Culturais na Globalização. A modernidade sem peias. Lisboa: Editorial Teorema.

Barth, Fredrik. 1998 [1969]. Ethnic Groups and Boundaries. The Social Organization of Culture Difference. Long Grove: Waveland Press.

Bourdieu, Pierre. 2007. Razóes práticas. Campinas: Papirus.

Ferreira,Vitor. 2003. "Uma polaroid sociográfica". Pp.23-50 in Vala, J. (coord.), Simetrias e Identidades. Jovens Negros em Portugal. Estudos sobre Juventude 8, Oeiras: Celta Editora.

Goffman, Erving. 1980. Estigma: notas sobre a manipulação da identidade deteriorada. Brasil: Edições Zahar [1963] 1993 [1959]. A Apresentação do Eu na Vida de Todos os Dias. Lisboa: Relógio D Água Editores.

Gusmão, Neuza. 2004. Os filhos da Africa em Portugal. Antropologia, mutliculturalidade e educação. Lisboa: Imprensa de Ciências Sociais.

Hall, Stuart. 2003. "As culturas nacionais como comunidades imaginadas". Pp. 47-63 in Hall, S., A identidade cultural na pós-modernidade. São Paulo: DP\&A Editora. 2000. "Questão Multicultural”. Pp. 51-100 in Sovik, L. (org.), Da Diáspora. Identidades e Mediações Culturais. Editora Universidade Federal de Minas Gerais. 1998. "Que negro é esse na cultura negra?” Pp. 335-349 in Sovik, L. (org.), Da Diáspora. Identidades e Mediaçôes Culturais, Minas Gerais: Editora Universidade Federal de Minas Gerais.

Jenkins, Richard. 2004. Social Identities. London: Routledge.

Juan, Edurne e Rodrigues, Donizeti. 2007. "Nu ta Valoriza Nós Raiz: el Rap Kriolo y la Construcción Identitaria de los Jóvenes de Origen Caboverdiano en el barrio de la Cova da Moura", Lisboa.

Les Back. 1996. New Ethnicities and Urban Culture: racisms and multiculture in young lives. London: University College London.

Lewis, G. e Phoenix, A. 2004."Race, ethnicity and identity". Pp. 115-150 in Woodward, K. (ed.), Questioning identity: gender, class, ethnicity. London: Routledge, The Open University. Moreira, Carlos. 2007. Património, Identidade e Nação. Lisboa: Instituto Superior de Ciências Sociais e Políticas. 
2006. “O enigma de Teseu, ou as identidades questionadas”, Pp. 15-34 in Peralta, E. e Anico, M. (Org.), Patrimónios e Identidades. Fiç̧ôes Contemporâneas, Oeiras: Celta Editora.

Novaes, Sylvia. 1993. Jogo de Espelhos: Imagens da representação de si através do espelho, São Paulo: Editora da Universidade de São Paulo.

Quintino, Maria. 2004. Migrações e Etnicidade em terrenos Portugueses. Guineenses: estratégias de invenção de uma comunidade. Lisboa: Instituto Superior de Ciências Sociais e Políticas.

Silva, José. 2003. O Discurso Contra Si Próprio. Lisboa: Assírio e Alvim.

Soares, L.; MV Bill; Athayde, C. 2005. Cabeça de Porco. Rio de Janeiro: Editora Objetiva.

Woodward, K. 2004. "Introduction” Pp. 1-4, in Woodward, K. (ed.), Questioning identity: gender, class, ethnicity. London: Routledge, The Open University.

\section{Contemplation and identity practices of youth in Cova da Moura (Amadora, PORTUGal)}

This article is based on research undertaken for the author's doctoral thesis "Kova-M forever: Samplagens da Zona. Identidades de Jovens da Cova da Moura [Samplings from the Zone. Youth identities in Cova da Moura]". The article aims to contribute to the discussion of the concept of identity and to foster an understanding of youth identities in the immigrant neighbourhood of Cova da Moura near Lisbon, Portugal. Fieldwork for the research relied on ethnographic methods like participant observation, semi-structured intervierws, informal conversations and the registration and analysis of images (graffiti/tattoos) and rap lyrics.

Keywords: identity, youth studies, migrant studies, neighbourhood studies, Portugal

Recebido em: 2012-08-13

Aceito em: 2012-10-03 